\title{
Miyoshi Muscular Dystrophy 1
}

National Cancer Institute

\section{Source}

National Cancer Institute. Miyoshi Muscular Dystrophy 1. NCI Thesaurus. Code C118846.

A rare, autosomal recessive inherited skeletal muscle disorder caused by mutation in the dysferlin gene. It affects young adults and is characterized by weakness and atrophy in the muscles of the upper and lower limbs. 